\title{
CUIDADOS PALIATIVOS: ENTRE AUTONOMIA E SOLIDARIEDADE
}

PALLIATIVE CARE: BETWEEN AUTONOMY AND SOLIDARITY

Ana Carolina Brochado Teixeira ${ }^{1}$

\section{Maria de Fátima Freire de Sá²}

Resumo: O conceito de saúde na contemporaneidade pressupõe um bem estar físico, psíquico e social. A forma de vivência da saúde, portanto, é individual, na medida em que cada pessoa arquiteta sua vida segundo os próprios valores. Por isso, faz parte indelével da ideia de saúde a autonomia corporal, tanto para a vida, quanto para a morte. A autonomia no processo do morrer tornou-se um direito fundamental, porquanto a população tem envelhecido consideravelmente e as doenças também têm se instalado de forma permanente. Quando o médico conclui que não há mais meios de cura, é possível que a pessoa se valha de cuidados paliativos, que são uma forma de cuidar do doente terminal - e não da doença. Trata-se de medidas que visam alívio da dor, tratamento mais humanizado que englobe a família, que o doente possa ficar em casa ou no lugar onde se sentir mais seguro, de modo que ele participe ativamente do seu processo de morrer, inserido no âmbito da sua construção biográfica. Pode-se, então, renunciar a tratamentos heroicos que objetivam apenas prolongar a vida, sem qualquer qualidade. Defende-se, nesse artigo, que os cuidados paliativos são parte do direito fundamental à saúde, pois a vida é um direito e não um dever, sendo possível a escolha por uma morte mais natural e que projete de forma mais íntegra os desejos do paciente, calcados na sua autonomia Palavras-chave: Cuidados paliativos. Autonomia. Solidariedade. Morte. Saúde.

$1 \quad$ Ana Carolina Brochado Teixeira. Doutora em Direito Civil pela UERJ, Mestre em Direito Privado pela PUC Minas, Especialista em Direito Civil pela Scuola di Diritto Civile di Camerino-Itália. Professora de Direito Civil do Centro Universitário UNA, Belo Horizonte-MG, Brasil. Pesquisadora do CEBID. Advogada. E-mail: anacarolina@teixeiraemirandaadvogados.com.br.

2 Maria de Fátima Freire de Sá, Doutora em Direito pela UFMG. Mestre em Direito pela PUC Minas. Professora do Curso de Graduação e do Programa de pós-graduação (mestrado e doutorado) em Direito da PUC Minas, Belo Horizonte, Minas Gerais, Brasil. Pesquisadora do CEBID. E-mail: mfatimasa@uol. com.br. 
Abstract: The concept of health in contemporary society presupposes good physical, mental and social welfare. The form of experiencing health, therefore, is individual insofar as each person architects their lives according to their own values. Thus, bodily autonomy is an indelible part of the idea of health, both for life and for death. The autonomy in the process of dying has become a fundamental right, considering that population has aged considerably and diseases have also been permanently installed. When the doctor concludes that there are no means of healing, it is possible for the person to receive palliative care, which is a way to take care of the terminally ill patient - and not of the disease. These are measures that aim to relieve pain, a more humane treatment involving the family, in which the patient can stay at home or other place able for feeling safer, in such a way that active participation in one's own process of dying is allowed, as part of the biographic construction. In this sense, one can renounce heroic treatments that aim only to prolong life, without any quality. It is argued in this article that palliative care is part of the fundamental right to health, for life is a right and not a duty, and it is possible to choose a more natural death which projects the patient's desires more straightforwardly, based in their autonomy. Keywords: Palliative care. Autonomy. Solidarity. Death. Health.

\section{INTRODUÇÃO}

"Quando você chegar a um dos muitos momentos da vida em que precisar refletir sobre si mesma, fornecer um relato do que foi, do que fez e do que significou para o mundo, peço - peço não, oro - para que não se esqueça de que você preencheu os dias de um homem à beira da morte com uma alegria plena, uma alegria que me foi desconhecida em todos os meus anos passados, uma alegria que não pede cada vez mais e, sim, descansa, saciada. E, neste momento, isso é algo enorme."

As palavras citadas na epígrafe foram escritas por Paul Kalanithi à sua filha Cady, pouco antes de morrer de câncer, aos trinta e sete anos de idade. Em O último sopro de vida, livro publicado no Brasil em 2016, Paul relatou sua experiência, tanto como médico, no início e ao longo de sua carreira, quanto sua experiência como paciente terminal: como eu podia ser tão autoritário usando um jaleco de cirurgião e tão humilde numa camisola de paciente?4

Paul foi residente-chefe do Hospital de Stanford e, infelizmente, a doença o surpreendeu em uma fase de vida em que não só a sua carreira, mas também a de sua esposa Lucy, estavam no auge. Com mestrado em Literatura e apaixonado

3 KALANITH, Paul. O último sopro de vida. Rio de Janeiro: Sextante, 2016, p. 148.

4 KALANITH, Paul. O último sopro de vida. Rio de Janeiro: Sextante, 2016, p. 19. 
por Filosofia e por todos os questionamentos que de seu estudo decorrem, especialmente a busca pelo sentido da vida, Paul escolheu a neurocirurgia como especialidade. Segundo ele, os neurocirurgiões trabalham com a essência da identidade: qualquer operação no cérebro é uma manipulação da substância de nosso eu. ${ }^{5}$

Da leitura do livro é possível depreender a importância singular que Paul dava às relações humanas, em especial, à relação médico-paciente. Com honestidade e sensibilidade, para além da excelência técnica, buscava orientar seus pacientes e suas famílias na compreensão da morte e da doença: Quando não pode usar o bisturi, as palavras são a única ferramenta do cirurgião.

Eis aí uma verdade: a morte, muitas vezes, não pode ser evitada pelo médico. Tampouco tem o médico o poder de devolver o doente, em determinadas situações, à sua vida anterior. Mas é dever do médico tomar a pessoa enferma pela mão e ajudá-la a encarar e a entender o sentido da própria vida.

Paul Kalanithi teve tempo para ter uma filha e para escrever um livro. E aí, o câncer começou a resistir às drogas recomendadas pela oncologista. A saúde decaiu rapidamente. Nova tomografia e nova ressonância magnética mostraram a piora do câncer nos pulmões e o aparecimento de outros tumores, inclusive no cérebro.

Ciente dos fatos, a prioridade de Paul, de sua família e de sua médica foi preservar a lucidez e otimizar a qualidade do tempo que restava a ele. Cuidados de conforto foram aplicados e ele, por fim, disse que se sentia pronto. Segundo relato de sua esposa: Ele queria dizer que estava pronto para remover o suporte respiratório, para começar com a morfina, para morrer. ${ }^{6}$

A comovente história do Dr. Paul Kalanithi foi contada para remeter o leitor a considerações sobre um valor, erigido à categoria de princípio jurídico: autonomia. Autonomia significa aptidão para a manifestação da vontade geradora de efeitos no mundo da vida. E, quando se fala em construir uma pessoalidade para a vida e para a morte, é preciso entender que alguns preferem morrer a viver permanentemente sedados ou incapazes; outros gostariam de lutar, a despeito da dor ou mesmo do estado de inconsciência.

Paul conseguiu se manifestar. Optou por não ser entubado. Também pediu que sua família estivesse presente, durante todo o processo do morrer. Aliás, pôde dizer a todos sobre seus sentimentos, suas angústias e seus medos. Despediuse dos pais, do irmão, da esposa, da filha e dos amigos. Pediu que seus escritos fossem publicados. Optou, ao final, pelos cuidados de conforto. E os momentos finais de Paul foram plenos de carinho, amor e cuidado:

$5 \quad$ KALANITH, Paul. O último sopro de vida. Rio de Janeiro: Sextante, 2016, p. 62.

6 KALANITH, Paul. O último sopro de vida. Rio de Janeiro: Sextante, 2016, p. 155. 
Os cálidos raios da luz da tarde começaram a entrar pelajanela do quarto, enquanto a respiração de Paul se tornava mais fraca. Cady esfregava os olhos com os punhos gordinhos pela aproximação da hora de dormir, e uma amiga chegou para levá-la para casa. Encostei a bochecha dela na de Paul, os tufos de cabelos escuros de ambos revirados da mesma forma, a expressão dele serena, a dela intrigada, porém tranquila, sem desconfiar de que aquela era uma despedida. Cantei em voz baixa a canção de ninar de Cady para os dois, em seguida deixei que ela fosse.

Quando o quarto escureceu com a noite, uma lâmpada mortiça foi acesa na parede, e as respirações de Paul ficaram entrecortadas e irregulares. Seu corpo continuava parecendo tranquilo, os membros relaxados. Pouco antes das nove horas, seus lábios se abriram e os olhos fecharam. Paul inspirou, para em seguida exalar seu último sopro de vida. ${ }^{7}$

É preciso deixar claro que, se a morte figurar como possibilidade no processo de construção da pessoalidade, ela deve ser considerada, não como afronta ao direito à vida, mas como realização de um projeto de vida boa de um destinatário ou coautor do direito que busca a realização de sua individualidade. Eis o objetivo desse texto. Discorrer sobre as escolhas das pessoas no processo do morrer. ${ }^{8}$ Há quem opte por cuidados paliativos, que "são uma abordagem para melhoria da qualidade de vida de pacientes e familiares que enfrentam uma doença ameaçadora da vida, através da prevenção e do alívio do sofrimento, através da identificação precoce e impecável avaliação e tratamento da dor e outros problemas, físicos, psicossociais e espirituais". ${ }^{9}$ Delimitado, portanto, seu âmbito de atuação: situações de terminalidade da vida e doenças incuráveis.

Os cuidados paliativos são objeto desse estudo, de forma a se verificar se o Direito brasileiro ampara sua aplicação no âmbito médico, tendo como fundamento jurídico o princípio da autonomia, que dá suporte à possibilidade da pessoa construir-se da maneira mais coerente com o seu modo de viver.

\section{Viver e morrer como processos complementares da construção do direito à saúde}

Desde o advento da Constituição Federal de 1988, que elevou ao status máximo no ordenamento pátrio relevantes princípios - tais como dignidade, liberdade, solidariedade e pluralismo - a busca pela realização pessoal, por meio

$7 \quad$ KALANITH, Paul. O último sopro de vida. Rio de Janeiro: Sextante, 2016, p. 157.

8 Sobre o tema: SÁ, Maria de Fátima Freire de; MOUREIRA, Diogo Luna. Autonomia para morrer: eutanásia, suicídio assistido, diretivas antecipadas de vontade e cuidados paliativos. $2^{\mathrm{a}}$ ed. Belo Horizonte: Del Rey, 2015.

9 GOMES, Ana Luisa Zaniboni; OTHERO, Marilia Bense. Cuidados paliativos. Estud. av. vol.30 no.88 São Paulo Sept./Dec. 2016. Disponível em http://www.scielo.br/scielo.php?script=sci_arttext\&pid=S010340142016000300155. Acesso em 6.7.17. 
do exercício das liberdades existenciais, passou a ser especialmente importante para o Direito. Em momentos mais sensíveis da vida humana, o agir livre é central para que a pessoa defina os rumos da sua existência de acordo com o seu projeto de vida boa. Tais definições formam um contexto de construção da vida privada, que deve ser respeitado pois cada indivíduo pode perseguir os próprios objetivos e viver conforme o estilo de vida por ele eleito, independentemente de ser ou não o da maioria.

Esse espaço sensível e autorreferente que marca os momentos mais importantes da existência humana delimita um campo para o exercício de liberdades existenciais garantido pela Constituição, no qual só são legítimas decisões tomadas pela própria pessoa; como afirma Stefano Rodotà, ${ }^{10}$ trata-se de matérias que são indecidibile per il legislatore, no qual compete ao legislador assegurar a possibilidade de escolha, mas seu conteúdo cabe unicamente ao indivíduo, como se fosse um lugar vazio cujo preenchimento deve ser garantido pela normatividade construída pela pessoa. ${ }^{11} \mathrm{O}$ controle do corpo, que pressupõe a autonomia privada, compõe essa seara, de modo que o exercício ou não de atos conservatórios da integridade física perpassam essa esfera de intimidade e privacidade, inclusive no processo do morrer.

Quando se trata do exercício de liberdades existenciais - mesmo que elas se refiram ao processo do morrer - é a consciência individual que deve estar no comando. Atitudes paternalistas - mesmo que expressem a solidariedade social - são ilegítimas, sob pena de se violar de forma imediata a dignidade da pessoa humana. Por isso, a forma do morrer deve respeitar a trajetória biográfica de cada um, razão pela qual não podem ser impostos tratamentos que violem as convicções individuais, pois o governo da própria vida e da própria morte deve ser gerenciado pela livre decisão do interessado.

O conceito de saúde na contemporaneidade pressupõe bem estar físico, psíquico e social. A forma de vivência desse direito fundamental, portanto, é pessoal, porquanto cada pessoa arquiteta sua vida segundo os próprios valores. Faz parte indelével da ideia de saúde a autonomia corporal, tanto para a vida, quanto para a morte. A autonomia no processo do morrer tornou-se um direito fundamental, cuja importância tem crescimento com o envelhecimento da população e, com isso, as doenças também têm se instalado de forma permanente. ${ }^{12}$

10 RODOTÀ, Stefano. Politici, liberateci dalla vostra coscienza. Disponível em: http://daleggere.wordpress.com/2008/01/13/stefano-rodota-\%C2\%ABpolitici-liberateci-dalla-vostra-coscienza\%C2\%BB/. Acesso em: 27 jul. 2016.

11 BODIN DE MORAES, Maria Celina. Uma aplicação do princípio da liberdade. In: BODIN DE MORAES, Maria Celina. Na medida da pessoa humana. Rio de Janeiro: Renovar, 2010, p. 183-206.

12 A ideia de autonomia corporal que ora se defende encontra limites na teoria dos direitos da personalidade, sistematizados no Código Civil e sujeitos à principiologia constitucional. Embora se defenda, nesse âmbito, que os direitos da personalidade possam ser exercidos pelo titular como autogestão do seu corpo, se está, pelo menos por ora, sujeito à extrapatrimonialidade, ou seja, autonomia corporal não 
Da mesma forma, defende-se que a saúde é construída por meio da noção individual de autonomia corporal, ${ }^{13}$ conformada segundo as próprias experiências físicas, biológicas, ambientais e sociais, pois é a partir das suas vivências que será possível construir seus valores e seu modelo de vida boa; afinal, a pessoa não apenas vive, ela convive e se relaciona. É sob esse parâmetro - individual e relacional - que a pessoa guia a própria vida e seu processo de morrer. Explicase: vida e morte são dois lados da mesma moeda, pois devem ser entendidos como direitos de liberdade complementares, principalmente quanto ao modo de vivenciá-los. É sob esse contexto que se pretende estudar os cuidados paliativos como escolha possível no processo de morrer, porquanto esse também deve ser permeado por opções que possam viabilizar que a morte seja espelho da forma pela qual a pessoa viveu a vida.

Os cuidados paliativos traduzem uma nova abordagem na Medicina focada na qualidade de vida e de morte, em situações em que o curar já não é mais possível. O termo palliare se origina no latim e significa proteger, amparar, cobrir, abrigar, ou seja, a perspectiva é do cuidado e não somente da cura. A Medicina Paliativa tem como princípios a escuta do paciente, o diagnóstico como etapa prévia ao tratamento, o conhecimento profundo dos medicamentos a serem utilizados e a utilização de remédios cujo escopo principal é o alívio e a simplicidade dos tratamentos. ${ }^{14}$ Os cuidados paliativos atuam, muitas vezes, sobre as circunstâncias da morte, quando se opta pela não manutenção da vida a qualquer custo, a qualquer sofrimento, a qualquer preço valorando, muito mais, a qualidade de vida e de morte e não a quantidade do tempo de vida que ainda se tem, em oposição à distanásia. Todavia, o que se impõe é o respeito ao desejo dos pacientes: tanto os que pretendem a submissão a todos os meios heroicos de manutenção da sua vida quanto aos que, ante uma doença terminal, pretendem cuidados paliativos, por meio da prevenção e controle de sintomas, intervenção psicossocial e espiritual, o paciente e a família vistos como unidade de cuidados, autonomia e independência, comunicação dialógica e trabalho em equipe multiprofissional.

Por isso, é possível afirmar que os cuidados paliativos derivam (i) do princípio da solidariedade. Esse princípio impõe uma série de deveres jurídicos de uns em relação a outros: "A solidariedade é a expressão mais profunda da sociabilidade que caracteriza a pessoa humana. No contexto atual, a lei maior implica em alienação de órgãos ou comercialização do corpo.

13 "[...] saúde é um conceito dinâmico, que muda conforme as experiências individuais, de modo que é possível afirmar que cada pessoa pode ter uma definição própria de saúde e, se ela tiver higidez psíquica, tem ampla liberdade para decidir sobre sua saúde, isto é, sobre seu corpo. Saúde, para nós, é o controle do próprio corpo". (TEIXEIRA, Ana Carolina Brochado. Saúde, corpo e autonomia privada. Rio de Janeiro: Renovar, 2010, p. 376).

14 MELO, Ana Georgia Cavalcanti de. Os cuidados paliativos no Brasil. Revista Brasileira de Cuidados Paliativos, ano 1, vol. 1, n. 1, 2008, p. 6. Disponível em http://www.cuidadospaliativos.com.br/img/din/ file/RBCP1.pdf. Acesso em 26.7.2016. 
determina - ou melhor, exige - que nos ajudemos, mutuamente, a conservar nossa humanidade, porque a construção de uma sociedade livre, justa e solidária cabe a todos e a cada um de nós." ${ }^{15}$ (ii) Mas, por outro lado, a opção por eles decorre do princípio da autonomia, na medida em que o doente recusa tratamentos heroicos e o apelo pelo desejo da cura e opta pelos cuidados de conforto, por meio dos quais se tenta alcançar maior leveza nessa dura realidade do morrer. Nesse contexto, os cuidados paliativos devem ser entendidos como parte do direito fundamental à saúde, pois a vida é um direito e não um dever, sendo possível a escolha por uma morte mais natural, com toda a qualidade possível nesse momento. É por isso que já se defendeu que "permitir que a pessoa determine o fim da sua pessoalidade é fazer com que ela realize, no momento da sua finitude, suas configurações enquanto agente da própria vida."16

\section{Estrutura e função dos cuidados paliativos}

O tratamento médico pode significar um sofrimento ainda maior, em virtude do mal-estar e dos efeitos colaterais que pode acarretar. Nesse sentido, pode ser melhor para o doente não insistir em um tratamento invasivo que possa violar a construção da sua pessoalidade, mas, sim, buscar medidas que aliviem a dor. Esses tratamentos que visam combater e evitar a dor são denominados cuidados paliativos, ou seja, "cuidados ativos totais prestados a pacientes e às suas famílias quando se estabelece que o paciente já não se beneficiará de tratamento (...). Nesse momento, o enfoque terapêutico é voltado para a qualidade de vida, o controle dos sintomas do doente e o alívio do sofrimento humano integrado pelo caráter trans, multi e interdisciplinar dos cuidados paliativos". ${ }^{17}$ Marcelo Sarsur defende que "a medicina paliativa apresenta-se como alternativa mais humana e benfazeja para os pacientes no fim da vida e se mostra afinada com o conceito de bem-estar físico, mental e social que se traduz no conceito de saúde". ${ }^{18}$

Em 2002, a Organização Mundial da Saúde aperfeiçoou o conceito de cuidados paliativos para entendê-lo como "abordagem que aprimora a qualidade de vida dos pacientes e famílias que enfrentam problemas associados com doenças ameaçadoras da vida, através da prevenção e alívio do sofrimento, por meio da identificação precoce, avaliação correta e tratamento da dor e outros problemas

15 BODIN DE MORAES, Maria Celina. O princípio da solidariedade. In: MATOS, Ana Carla Harmatiuk. (org.), A construção dos novos direitos. Porto Alegre: Nuria Fabris, 2008, p. 247.

16 SÁ, Maria de Fátima Freire de; MOUREIRA, Diogo Luna. Autonomia para morrer: eutanásia, suicídio assistido, diretivas antecipadas de vontade e cuidados paliativos. $2^{a}$ ed. Belo Horizonte: Del Rey, 2015, p. 156.

17 BRASIL. Ministério da Saúde. Instituto Nacional do Câncer. Cuidados paliativos oncológicos: controles de sintomas. Rio de Janeiro: INCA, 2001, p. 5. Disponível em: http://www.inca.gov.br/publicacoes/ manual_cuidados.pdf. Acesso em: 10 ago. 2009.

18 SILVA, Marcelo Lucas Sarsur da. Do direito a não sentir dor: fundamentos bioéticos e jurídicos do alívio da dor como direito fundamental. Tese (doutorado) 2014. $141 \mathrm{fls}$. Universidade Federal de Minas Gerais, Faculdade de Direito, Belo Horizonte, 2014, p. 111. 
de ordem física, psicossocial e espiritual". ${ }^{19}$

A mudança ampliou os cuidados paliativos para além da terminalidade, estendendo-o, também, a pessoas com doenças incuráveis, com a finalidade de se alcançar o controle total da dor de forma mais humanitária. Os princípios dos cuidados paliativos são:

controle da dor e dos sintomas correlatos, o que é conseguido não por meio de protocolos fixos, mas pela avaliação da individualidade; considerar a morte não como um fracasso da medicina, mas sim como nossa mais intrínseca característica; oferecer qualidade de vida, através do bem-estar físico, psicológico e espiritual, sempre respeitando a crença, ou a falta de, do paciente; não abreviar a vida, mas também não praticar obstinação terapêutica; desenvolver um atendimento multiprofissional, necessário devido à limitação de cada profissão; resgatar a identidade pessoal, através do cuidado da dor total, quando então se estará tratando o sofrimento. Também através da comunicação aberta com o paciente e seus familiares; estabelecer com o paciente e seus familiares uma comunicação aberta, já que o compartilhar de verdades facilita a adaptação à nova realidade, além de resgatar o valor do paciente como pessoa dotada de competência e autonomia; oferecer apoio aos familiares, o que se estende à fase do luto. ${ }^{20}$

Trata-se, como dito anteriormente, de cuidado ativo que proporcione ao paciente o maior bem-estar possível no contexto da terminalidade e de doenças incuráveis - embora pareça situação contraditória, não o é, na medida em que se entende viver e morrer como situações complementares da vida. Equipes multidisciplinares ${ }^{21}$ apoiarão o paciente no enfrentamento de seus medos e suas dores - o sofrimento físico, psicológico, espiritual e social - a também a família. Afinal, o estigma e as consequências da enfermidade não se esgotam na pessoa do doente. Os familiares cuidadores são também vítimas do impacto da doença. Não raro, enfrentam problemas financeiros pela mudança de vida; enfrentam a solidão e o isolamento social ocasionado pelo longo tempo de enfermidade. E, diante de tantas intempéries, o corpo e a mente adoecem. ${ }^{22}$

19 LOPES, Ruth Gelehrter da Costa; OLIVEIRA, João Batista Alves de. Cuidados paliativos: A necessidade na medicina atual diante do paciente fora da possibilidade terapêutica de cura. Prática Hospitalar, ano IX, n. 51, p. 168, maio-jun. 2007.

20 LOPES, Ruth Gelehrter da Costa; OLIVEIRA, João Batista Alves de. Cuidados paliativos: A necessidade na medicina atual diante do paciente fora da possibilidade terapêutica de cura. Prática Hospitalar, ano IX, n. 51, p. 168, maio-jun. 2007.

21 A equipe deverá ser composta por médico, enfermeiro, psicólogo, assistente social, farmacêutico, nutricionista, terapeuta ocupacional, além de voluntários.

22 "Los esposos que se convierten en cuidadores son más propensos al estrés al tener que adaptarse a nuevas necesidades y modificar su vida laboral, sexual y social, por lo que corren un alto riesgo de ver deteriorada su salud física; reducen su tiempo libre; a veces deben abandonar su trabajo y con fre- 
Essa ideia originou os hospices - que significa abrigo, refúgio, asilo de doentes desamparados ou à beira da morte -, "lugar onde são atendidos os pacientes fora dos recursos de cura", que "surge exatamente dessa tendência de não lutar contra enfermidades incuráveis já em fase terminal. Esses estabelecimentos visam aproximar-se mais de uma casa do que de um hospital, onde são ministrados apenas cuidados paliativos, não mais curativos (...)". ${ }^{23}$ Principalmente na tentativa de controlar a dor, medicamentos são usados de forma regular, para prevenir dores crônicas, e não ações posteriores a sintomas de dor. Também buscam incluir a família nesse processo de uma morte mais natural e indolor. Além de satisfação de necessidades físicas, objetivam-se também cuidados psicológicos e espirituais, já que o direito fundamental à saúde visa o alcance do bem-estar físico, psíquico e social.

A função dos cuidados paliativos é conseguir a máxima qualidade de vida possível para pacientes e seus familiares, de modo que a morte seja vivenciada como situação natural e complementar à vida. A ideia não é acelerar nem incentivar a morte, mas auxiliar que esse processo de morrer possa ser mais próximo dos desejos do paciente, além de incluir a família nessa rede de cuidados.

É tal a importância que esses cuidados vêm tomando que alguns países o reconhecem como verdadeiro direito, como o fez o Ministerio de Sanidad e Consumo (Espanha), ao criar um Plano Nacional de Cuidados Paliativos, para que os pacientes tenham acesso a ele em qualquer lugar, circunstância ou situação, através de diferentes estruturas das redes de saúde, com apoio psicológico e auxílio social que necessitem, sem distinção do tipo de doença. ${ }^{24}$

A ideia de cuidados paliativos deve ser compreendida para além da simples renúncia a tratamento médico que vise prolongar a vida, mas, sim, como um tratamento integral da pessoa, que lhe confira maior qualidade de vida, mesmo que isso implique em viver menos. A tutela integral da pessoa humana impõe uma mudança substancial: não mais se busca viver por mais tempo, mas com mais qualidade.

Os cuidados paliativos não se restringem unicamente à pessoa do paciente, mas também àqueles que estão a sua volta e compartilham do sofrimento, ainda que em outra dimensão. Isso porque o estado emocional do cuidador e dos familiares pode repercutir sobre o estado emocional do enfermo. Também porque o transtorno emocional que padece o cuidador, enquanto o paciente

cuencia califican como excesiva la carga que implican dichos cuidados. Se ha comprobado que quienes cuidan personas con un mayor nível de dependencia manifiestan más problemas de salud, por lo que necesitan también apoyo y atención (Vera, 2005)." (BARROSO FERNÁNDEZ, Irene de la C. y GRAU ABALO, Jorge. Eutanasia y cuidados paliativos: diferentes aristas de un mismo problema? Psicologia y salud, Vol.22, Núm.1:5-25, enero-junio de 2012, p.10).

23 PATIÑO, Ana Paula Corrêa. Limitações ao direito de recusar tratamento médico ou intervenção cirúrgica. São Paulo: Universidade de São Paulo, Faculdade de Direito, 2005, p. 45 Dissertação (Mestrado).

24 BAYÉS, Ramón. Afrontando la vida, esperando la muerte. Madrid: Alianza, 2006, p. 21. 
se aproxima da morte ou no momento do falecimento, pode adoecê-lo no seu processo de luto. ${ }^{25} \mathrm{O}$ cuidado com o cuidador é tão importante que a OMS, ao propor a definição de cuidados paliativos, incluiu-os entre os merecedores dessa atenção especial.

Nos Estados Unidos, tem-se desenvolvido o Counselling como metodologia para aplicação dos cuidados paliativos. O Counselling surgiu nos EUA, nos anos 50 do século $X X$, e na Europa, na década de 70 do século $X X$, particularmente na Inglaterra. Inicialmente tratava-se de um serviço de orientação como instrumento de suporte nos serviços sociais e no voluntariado. Foi com Carl Rogers, psicólogo estadunidense, que o termo assumiu os contornos atuais de colóquio centrado sobre o paciente.

Trata-se de metodologia ou estratégia imprescindível para a comunicação de questões médicas entre o profissional da saúde, o paciente e seus familiares, de modo que a transmissão de más notícias seja feita de forma solidária. No âmbito dos cuidados paliativos, o Counselling tem como escopo a diminuição da experiência de sofrimento, facilitando o processo de adaptação dos pacientes e das famílias à situação em que se encontram. Desse escopo final, derivam-se os seguintes objetivos mediatos: a) diminuir a morbidade psicológica subjacente às situações de ameaça e incerteza; b) incrementar os recursos internos e externos de todos os intervenientes na interação clínica; c) diminuir a vulnerabilidade da pessoa; d) cuidar do cuidador familiar; e e) cuidar do profissional. ${ }^{26}$

Cuidados paliativos constituem, portanto, um direito do paciente; a pessoa tem a legítima expectativa de utilização da melhor metodologia para a aplicação desses cuidados, de modo que o Counselling se torna uma alternativa bastante interessante para transmitir a verdade de forma mais amena. ${ }^{27}$

\section{Os cuidados paliativos na legislação estrangeira}

Vários países possuem regramento específico sobre cuidados paliativos. A Itália regulamentou-os por meio da Lei $n^{\circ}$ 38, de 15 de março de 2010, cujo escopo é garantir o acesso aos cuidados paliativos e às terapias contra a dor, a fim de assegurar o respeito à dignidade e da autonomia da pessoa humana, suas necessidades de saúde, a equidade no acesso, na assistência e na qualidade do tratamento.

Pela Lei, os cuidados paliativos visam assegurar um programa de tratamento individual para o doente e sua família, tendo como norte os seguintes princípios

25 BAYÉS, Ramón. Afrontando la vida, esperando la muerte. Madrid: Alianza, 2006, p. 193.

26 ARRANZ, Pilar; BARBERO, Javier; BARRETO, Pilar; BAYÉS, Ramon. Intervención emocional en cuidados paliativos: modelos y protocolos. Barcelona: Ariel Ciencias Médicas, 2010, p. 35-36.

27 LIMA, Taisa Macena de Lima; SÁ, Maria de Fátima Freire de. Ensaios sobre a velhice. Belo Horizonte: Arraes, 2015, p.92. 
fundamentais: a tutela da dignidade e da autonomia do doente sem qualquer discriminação, a proteção e a promoção da qualidade de vida no momento do seu fim, o adequado apoio no tratamento e sócio-assistencial da pessoa doente e da sua família (art. $1^{\circ}$ ).

A Lei italiana define cuidados paliativos como o conjunto das intervenções terapêuticas, diagnósticas e assistenciais, voltadas para a pessoa doente e para o seu núcleo familiar, através de cuidados ativos e totais do paciente cuja doença, caracterizada por evolução contínua e irreversível e péssimo prognóstico, não mais responde a tratamentos específicos. Determina a criação de duas redes - uma regional e outra nacional - de cuidados paliativos e da terapia da dor, para fomentar a constante adequação da estrutura dos serviços de saúde às exigências do doente.

Além disso, a Lei n 38/2010 determina que conste nos prontuários maiores informações sobre as características da dor manifestada pelo paciente, bem como sobre os recursos utilizados para combatê-la. Para esses fins, os médicos deverão ter formação e preparação específica para tratarem esse tipo de paciente, além de maior simplificação dos procedimentos de acesso aos remédios empregados na terapia da dor.

A Lei portuguesa sobre o tema foi promulgada em 2012 (Lei $n^{\circ}$ 52) e conceitua essa modalidade de cuidados como:

ativos, coordenados e globais, prestados por unidades e equipas específicas, em internamento ou no domicílio, a doentes em situação em sofrimento decorrente de doença incurável ou grave, em fase avançada e progressiva, assim como às suas famílias, com o principal objetivo de promover o seu bem-estar e a sua qualidade de vida, através da prevenção e alívio do sofrimento físico, psicológico, social e espiritual, com base na identificação precoce e do tratamento rigoroso da dor e outros problemas físicos, mas também psicossociais e espirituais (Base II, conceitos).

E tem como vetor, para sua implementação, o respeito à "autonomia, a vontade, a individualidade, a dignidade da pessoa e a inviolabilidade da vida humana" (Base III, 2), denotando o reconhecimento da relevância da construção biográfica de cada pessoa, que pode fazer do processo de morrer um espelho das opções retratadas durante $o$ viver.

Com base em tais premissas, a lei adotou os seguintes princípios:

a) Afirmação da vida e do valor intrínseco de cada pessoa, considerando a morte como processo natural que não deve ser prolongado através de obstinação terapêutica; b) Aumento da qualidade de vida do doente 
e sua família; c) Prestação individualizada, humanizada, tecnicamente rigorosa, de cuidados paliativos aos doentes que necessitem deste tipo de cuidados; d) Multidisciplinaridade e interdisciplinaridade na prestação de cuidados paliativos; e) Conhecimento diferenciado da dor e dos demais sintomas; f) Consideração pelas necessidades individuais dos pacientes; g) Respeito pelos valores, crenças e práticas pessoais, culturais e religiosas; h) Continuidade de cuidados ao longo da doença.

Vê-se que, além de uma normativa própria sobre cuidados paliativos - o que representa importante avanço na mudança de paradigma do trato da saúde e da doença - eles devem ser moldados de acordo com as aspirações individuais, não sendo uma imposição do médico ao doente e à família, mas uma construção do que, dentro do contexto da doença, é o melhor para o paciente, em um verdadeiro diálogo de adequação.

Para tanto, o doente tem uma série de direitos que vão desde a informação adequada sobre a sua situação nos limites da sua vontade, até o recebimento de cuidados paliativos, de acordo com as suas necessidades, que aliviem a dor e outros sintomas, no local onde escolher (exceto em casos urgentes). Também lhe é assegurado participar das decisões sobre seu tratamento e o momento de interrompê-lo, o respeito à sua privacidade e à confidencialidade dos dados pessoais (Base $V$, I). As liberdades existenciais previstas em lei são facultadas a todos, independente de condição financeira, além de garantir que as pessoas com qualquer abalo em seu discernimento, possam expressar vontade, a qual deverá ser levada em consideração pelo médico.

Aos familiares também são concedidos direitos semelhantes, embora mais reduzidos do que os do paciente, quais sejam: receber apoio que facilite o processo de luto, participar da escolha do local de aplicação dos cuidados paliativos, receber informações sobre o estado clínico do doente (se esta for a sua vontade), participar das decisões sobre cuidados paliativos a serem prestados aos doentes e à família, além de receber informações objetivas sobre condições de internamento (Base VI).

A Lei também prevê deveres ao Estado, tais como a prestação de cuidados paliativos, a instituição de políticas públicas, bem como promoção, enquadramento e incentivo do voluntariado para o cumprimento das finalidades da lei. Além disso, determina a criação de uma Rede Nacional de Cuidados Paliativos (RNCP), cujo objetivo principal é a prestação de cuidados paliativos a pessoas doentes que, independentemente da idade e patologia, estejam numa situação de sofrimento decorrente de doença grave ou incurável, com prognóstico limitado e em fase avançada e progressiva. 


\subsection{Entre os cuidados paliativos e a opção pela morte assistida}

Em 2002, a Bélgica legalizou a prática da eutanásia (The Belgian Act on Euthanasia of May, 28th 2002), em instrumento que contém determinações que abrangem os cuidados paliativos. Isso porque um dos requisitos para a prática da eutanásia é a informação, dada pelo médico ao paciente, sobre sua condição de saúde, as opções terapêuticas possíveis, a viabilidade dos cuidados paliativos e suas implicações. ${ }^{28}$

A partir de 2013, a referida Lei da Eutanásia sofreu modificações, mais voltadas para a competência do doente para emitir sua vontade. Se antes o ato era permitido para maiores e menores emancipados, a alteração legislativa passou a permitir a prática do ato independente de limite de idade. A Bélgica é o primeiro país no mundo a abolir legalmente todas as restrições de idade para a realização da eutanásia. Com a expansão da Lei da Eutanásia, o menor com discernimento, também pode requerer a prática da morte assistida desde que apresente situação médica de sofrimento físico insuportável devido a uma doença terminal intratável. Os pacientes maiores e emancipados devem apresentar sofrimento físico ou psíquico insuportável e intratável.

A insuportabilidade é um elemento subjetivo e só pode ser avaliada pelo paciente. Porém, é importante que haja uma concordância entre médico e paciente sobre a extensão do sofrimento físico e/ou mental. Já a intratabilidade é um termo objetivo porquanto qualquer opção terapêutica deve conter três requisitos: a) oferecimento de uma melhora efetiva; b) possibilidade de administrar o tratamento em um período razoável; c) equiparação entre os benefícios e os prejuízos gerados pelo tratamento. ${ }^{29}$

Em virtude dessas novas disposições da Lei belga, despertou-se para a necessidade de maior aprofundamento no estudo dos cuidados paliativos pediátricos, que têm suas peculiaridades em função da pouca idade do paciente.

28 Neste sentido vide capítulo II, Seção 3, da Lei Belga: BELGIUM. The BelgianAct on Euthanasia of May 28th 2002. Disponível em: <http://www.ethical-perspectives.be/viewpic.php?LAN=E\&TABLE=EP\&ID=59>. Acesso em 26 jul. 2016; Os demais requisitos são: a) o paciente deve emitir sua decisão de forma voluntária e razoável; b) o sofrimento físico ou mental deve ser inconteste e contínuo; c) o médico deve consultar outro profissional acerca do diagnóstico do paciente que corrobore a natureza grave e incurável da doença; d) o médico deve se certificar de que o paciente pôde discutir seu pedido com outras pessoas do seu interesse.

29 '“Unbearable' suffering can be understood as a subjective term. By its nature, the extent to which the suffering is unbearable must be determined from the perspective of the patient himself or herself, and may depend on his or her physical and mental strenght and personality. According to the Law, a physician has to come to a level of mutual understanding with the patient about the extent of his or her unendurable suffering. 'Untreatable' is a more objective term. According to the guidelines of the Dutch Psychiatric Association (NVvP), any therapeutic option for a particular condition must meet the following three requirements: (1) it must offer a real prospect of improvement, (2) it must be possible to administer adequate treatment within a reasonable period of time and (3) there must be a reasonable balance between the expected treatment results and the burden of treatment consequences for the patient." (THIENPONT L et al. Euthanasia requests, procedures and outcomes for 100 Belgian pacients suffering from psychiatric disorders: a retrospective, descriptive study. BMJ Open, 2015; 5: e007454. p. 2). 
A Association for Children's Palliative Care (ACT) define os cuidados paliativos pediátricos como uma abordagem ativa que visa o cuidar longitudinal: desde o diagnóstico da doença, durante a vida da criança, na morte e mesmo na fase de luto. Engloba elementos físicos, emocionais, sociais e espirituais, com enfoque na melhoria da qualidade de vida da criança ou jovem, incluindo o manejo de sintomas de desconforto, e no apoio à família, na morte e durante o luto. Ao contrário dos cuidados paliativos de adultos, nas crianças o prolongamento da vida pode ser um objetivo importante. Esses cuidados são, portanto, orientados não só para a criança que sofre de, mas também para a criança que vive com e seria isso apesar da doença. ${ }^{30}$

Os cuidados paliativos com crianças devem ser divididos em fases: a) contato com equipe de cuidados, em face do reconhecimento que o cuidado afigurase a terapia mais eficiente em face da impossibilidade da cura; b) contato da equipe com a criança e a família, a fim de prever um plano de apoio integral, com estabelecimento de uma relação de confiança mútua; c) manutenção dos cuidados paliativos, de modo a proporcionar estabilidade à criança e à família; d) fase terminal, com foco no controle dos sintomas e consideração prévia do luto, tanto da criança quanto dos familiares e, na medida do possível, no planejamento da morte; e) fase do luto. Estudos também demonstram que a participação da criança nas decisões sobre seu tratamento é importante e proporciona conforto à família. Ao revés, os pais que definem o tratamento sem consultar os filhos se arrependem posteriormente. ${ }^{31}$

Diante dessa abertura da legislação belga, houve relevante alerta à comunidade científica a respeito do "limbo" sobre o tema, razão pela qual muito ainda há que se desenvolver a fim de prestar cuidados paliativos adequados para a população menor de idade. ${ }^{32}$ Pesquisadores apontam a necessidade de avaliar individualmente cada criança e sua família, tendo como ponto de partida o respeito às suas crenças e valores, o que facilitará a comunicação. Esses cuidados deverão atuar, inclusive, na fase do luto familiar. ${ }^{33}$

30 NUNES, Rui; SILVA, Filipa Martins. Caso belga de eutanásia em crianças. Rev. Bioét. vol.23 no.3 Brasília set./dez. 2015. Disponível em http://www.scielo.br/scielo.php?script=sci_arttext\&pid=S198380422015000300475\&lng=pt\&nrm=iso. Acesso em 27.7.16.

31 NUNES, Rui; SILVA, Filipa Martins. Caso belga de eutanásia em crianças. Rev. Bioét. vol.23 no.3 Brasília set./dez. 2015. Disponível em http://www.scielo.br/scielo.php?script=sci_arttext\&pid=S198380422015000300475\&lng=pt\&nrm=iso. Acesso em 27.7.16.

32 "O controle impecável da dor e de outros sintomas é a principal estratégia na abordagem das crianças que necessitam de cuidados paliativos. Mas são poucas as pesquisas sobre o manejo da dor e dos sintomas nos cuidados paliativos em pediatria, principalmente quando comparadas ao extenso leque de estudos referentes aos pacientes adultos." (MOTA, Joaquim Antônio Cesar; OLIVEIRA, Benigna Maria de; VALADARES, Maria Thereza Macedo. Cuidados paliativos em pediatria: uma revisão. Rev. Bioét. vol.21 no.3 Brasília set./dez. 2013. Disponível em http://www.scielo.br/scielo.php?script=sci_ arttext\&pid=S1983-80422013000300013\&Ing=pt\&nrm=iso. Acesso em 25.7.16)

33 MOTA, Joaquim Antônio Cesar; OLIVEIRA, Benigna Maria de; VALADARES, Maria Thereza Mace- 
De toda maneira, importante aqui frisar que a Lei da Eutanásia permite ao paciente a opção por cuidados paliativos ou pela morte assistida, seja através do auxílio ao suicídio, seja através da eutanásia ativa.

\section{Cuidados paliativos e sua aplicação no direito brasileiro}

O Brasil não tem legislação específica sobre cuidados paliativos. Seu cabimento, portanto, decorre de interpretação da principiologia constitucional, da qual se depreende a possibilidade de melhor cuidar do paciente, ao invés de aplicar medidas heroicas sem qualquer resultado útil, quando não mais é possível curar. Autonomia e solidariedade aqui se interrelacionam, porquanto o paciente tem direito de escolher os tratamentos e não tratamentos que deseja, e o médico tem o dever de tratá-lo da melhor forma possível, dentro dos limites definidos pelo paciente. Tudo isso em nome da sua dignidade, uma vez que ninguém será submetido a tratamento desumano ou degradante (art. $5^{\circ}$, III, Constituição da República), consoante dispõem diversos diplomas legislativos, tais como Código Civil, Lei n 8.080/90 - Lei Orgânica da Saúde e Carta dos Direitos dos Usuários da Saúde (Portaria no 1.820, de 13.8.2009 do Ministério da Saúde). ${ }^{34}$

De acordo com o Código de Ética Médica, o manejo dos cuidados paliativos é autorizado ao médico, pois, do mesmo modo que morte e vida exercem uma relação de complementariedade, as terapias curativa e paliativa não são mais lados opostos. Por isso, a doutrina propõe uma atuação mais intensa na formação do médico, a fim de beneficiar toda a equipe envolvida no tratamento, principalmente o paciente..$^{35}$

Na compreensão dos direitos do paciente, em novembro de 2006, o Conselho Federal de Medicina editou a Resolução $n^{\circ}$ 1.805/2006, regulamentando uma prática que já se fazia corriqueira nas UTI's: a suspensão de procedimentos e tratamentos que prolonguem a vida de paciente terminal. ${ }^{36}$ Assim, 0 art. do. Cuidados paliativos em pediatria: uma revisão. Rev. Bioét. vol.21 no.3 Brasília set./dez. 2013. Disponível em http://www.scielo.br/scielo.php?script=sci_arttext\&pid=S1983-80422013000300013\&lng=pt\&nrm=iso. Acesso em 25.7.16.

34 "Art. $4^{\circ}$ Toda pessoa tem direito ao atendimento humanizado e acolhedor, realizado por profissionais qualificados, em ambiente limpo, confortável e acessível a todos. Parágrafo único. É direito da pessoa, na rede de serviços de saúde, ter atendimento humanizado, acolhedor, livre de qualquer discriminação, restrição ou negação em virtude de idade, raça, cor, etnia, religião, orientação sexual, identidade de gênero, condições econômicas ou sociais, estado de saúde, de anomalia, patologia ou deficiência, garantindo-lhe: (...) X - a escolha do local de morte; XI - o direito à escolha de alternativa de tratamento, quando houver, e à consideração da recusa de tratamento proposto;"

35 MOTA, Joaquim Antônio Cesar; OLIVEIRA, Benigna Maria de; VALADARES, Maria Thereza Macedo. Cuidados paliativos em pediatria: uma revisão. Rev. Bioét. vol.21 no.3 Brasília set./dez. 2013. Disponível em http://www.scielo.br/scielo.php?script=sci_arttext\&pid=S1983-80422013000300013\&lng=pt\&nrm=iso. Acesso em 25.7.16.

36 "Art. $1^{\circ}$ É permitido ao médico limitar ou suspender procedimentos e tratamentos que prolonguem a vida do doente em fase terminal, de enfermidade grave e incurável, respeitada a vontade da pessoa ou de seu representante legal." (CONSELHO FEDERAL DE MEDICINA. Resolução no. 1.805/2006. Disponível em: http://www.portalmedico.org.br/resolucoes/cfm/2006/1805_2006.htm. Acesso em: 17 jul. 
$1^{\circ}$ possibilita a suspensão ou a limitação, pelo médico, de procedimentos e tratamentos que prolonguem a vida de pessoa em fase terminal, desde que respeitada a vontade dela ou de seu representante legal. Caberá ao médico o dever de esclarecer ao doente ou a seu representante legal as modalidades terapêuticas adequadas (parágrafo $1^{\circ}$ ).

A Resolução n $1805 / 2006$ também determina, no art. $2^{\circ}$, que o doente continuará a receber todos os cuidados necessários para aliviar os sintomas que levam ao sofrimento, assegurada a assistência integral, o conforto físico, psíquico, social e espiritual. O direito de alta hospitalar também é garantido ao paciente.

Embora contestada pelo Ministério Público, através de ação civil pública que visou suspender seus efeitos, em 2010, houve sentença reconhecendo sua validade, pois seu objeto é garantir uma conduta médica humanista, quando não há mais possibilidades de cura, o que não ofende o ordenamento jurídico posto.

De fato, a Resolução reconhece a autonomia do paciente perante a possibilidade de suspensão dos tratamentos médicos. A decisão não é do médico. Ele tem, tão somente, a obrigação de informar ao paciente seu prognóstico. O que não impede que o paciente procure outras opiniões e meios de tratamento. ${ }^{37}$

Nesse mesmo sentido, o Código de Ética Médica (Resolução CFM n ${ }^{\circ}$ 1931/2009): ${ }^{38}$

Cap. I - Dos princípios fundamentais XXII - Nas situações clínicas irreversíveis e terminais, o médico evitará a realização de procedimentos diagnósticos e terapêuticos desnecessários e propiciará aos pacientes sob sua atenção todos os cuidados paliativos apropriados.

Art. 41. (...) Parágrafo único. Nos casos de doença incurável e terminal, deve o médico oferecer todos os cuidados paliativos disponíveis sem empreender ações diagnósticas ou terapêuticas inúteis ou obstinadas, levando sempre em consideração a vontade expressa do paciente ou, na sua impossibilidade, a de seu representante legal.

É importante salientar que se a morte não é tratada pela pessoa como uma construção biográfica, não há que se falar em imposição do morrer, sob pena de tal conduta se mostrar juridicamente indevida, tal como a negação da própria autonomia para morrer. Cabe à pessoa, portanto, definir quais possibilidades são capazes de efetivar a construção de sua pessoalidade; e ao Direito, reconhecer e efetivar tais escolhas.

2016).

37 SÁ, Maria de Fátima Freire de; NAVES, Bruno Torquato de Oliveira. Manual de biodireito. $3^{a}$ ed. Belo Horizonte: Del Rey, 2015, p. 396.

38 Disponível em http://www.portalmedico.org.br/resolucoes/cfm/2009/1931_2009.htm. Acesso em 1.8.2016. 
Optando a pessoa por cuidados paliativos, ou mesmo na hipótese de autonomia prospectiva apontando tal caminho, eles devem ser realizados no paciente, assegurando-lhe dignidade no final da vida. E assim, enquanto a morte não se concretiza, o enfermo é tratado na sua integralidade, por meio do tratamento adequado à situação de terminalidade.

\section{CONSIDERAÇÕES FINAIS}

Em meio ao sofrimento provocado por um dano cerebral grave, não são apenas os médicos que perdem de vista o significado da situação: as famílias tampouco costumam percebê-lo. Elas veem o passado, as memórias, os amores recentes, tudo representado pelo corpo danificado diante delas. Eu - o médico - vejo os futuros prováveis: os aparelhos de respiração artificial ligados pela abertura cirúrgica no pescoço, o líquido pastoso pingando por um buraco na barriga, a longa e dolorosa recuperação parcial, a possibilidade de o paciente nunca voltar a ser o que era antes. Nesses momentos eu não agia como inimigo da morte, mas como seu embaixador. Eu precisava ajudar aquelas famílias a entender que a pessoa que conheciam - o ser humano inteiro, vital e independente - ficara para trás. E eu precisava da ajuda delas para compreender que tipo de futuro o paciente desejaria: uma morte fácil e tranquila ou uma prisão entre sacos de fluidos, persistindo na vida embora não fosse capaz de lutar por ela. ${ }^{39}$ (KALANITH, 2016, p. 73)

A opção por cuidados paliativos se apresenta como alternativa médica para os casos de terminalidade nos quais a pessoa não vislumbra a morte assistida como uma possibilidade do seu projeto de construção de pessoalidade. Essa afirmação pode ser constatada pela experiência de vários países, dentre eles a Bélgica, cuja legislação permite tanto a escolha pela eutanásia ou pelo auxílio ao suicídio, quanto a adoção de cuidados paliativos.

De toda maneira, para se construir uma autonomia para morrer como projeto de pessoalidade, imprescindível saber quais interesses críticos e experienciais compõem a visão de vida boa daquele que busca cuidados paliativos ou a morte assistida. Todavia, cumpre esclarecer que mesmo em se optando pela morte assistida, nos países em que ela é possível, o ato não se desvincula dos cuidados que devem ser oferecidos ao final da vida para aliviar o sofrimento e preservar o máximo de bem-estar.

Mas, e quando não for possível a escolha? É possível pensar naquelas pessoas que se encontram em fase terminal, mas que não têm qualquer possibilidade de manifestação de vontade. Não escreveram suas diretivas antecipadas de

KALANITH, Paul. O último sopro de vida. Rio de Janeiro: Sextante, 2016, p. 73. 
vontade. Caberá aos familiares a decisão pelos cuidados paliativos? Ao médico? Uma opção compartilhada entre familiares e profissionais, no melhor interesse do paciente?

A reconstrução da vontade do paciente, extrajudicial ou judicial, depende da sensibilidade daqueles que fizeram parte da sua vida; isso porque não se trata de assegurar a vontade da família, mas, sim, assegurar a vontade da pessoa enferma, reconstruída a partir das suas relações com seus familiares, sua equipe médica e seus amigos. Só assim se dará a efetivação da dignidade no morrer: pela conscientização de que cada um tem seus próprios interesses, cada pessoa é dotada de um padrão moral que lhe é próprio.

\section{REFERÊNCIAS DAS FONTES CITADAS}

ARRANZ, Pilar; BARBERO, Javier; BARRETO, Pilar; BAYÉS, Ramon. Intervención emocional en cuidados paliativos: modelos y protocolos. Barcelona: Ariel Ciencias Médicas, 2010.

BARROSO FERNÁNDEZ, Irene de la C. y GRAU ABALO, Jorge. Eutanasia y cuidados paliativos: diferentes aristas de un mismo problema? Psicologia y Salud, Vol.22, Núm.1:5-25, enero-junio de 2012.

BAYÉS, Ramón. Afrontando la vida, esperando la muerte. Madrid: Alianza, 2006.

BODIN DE MORAES, Maria Celina. O princípio da solidariedade. In: MATOS, Ana Carla Harmatiuk. (org.), A construção dos novos direitos. Porto Alegre: Nuria Fabris, 2008.

BODIN DE MORAES, Maria Celina. Uma aplicação do princípio da liberdade. In: BODIN DE MORAES, Maria Celina. Na medida da pessoa humana. Rio de Janeiro: Renovar, 2010.

GOMES, Ana Luisa Zaniboni; OTHERO, Marilia Bense. Cuidados paliativos. Estud. av. vol.30 no.88 São Paulo Sept./Dec. 2016. Disponível em http://www.scielo.br/scielo.php?script=sci_arttext\&pid=S010340142016000300155. Acesso em 6.7.17.

KALANITH, Paul. O último sopro de vida. Rio de Janeiro: Sextante, 2016.

LIMA, Taisa Macena de Lima; SÁ, Maria de Fátima Freire de. Ensaios sobre a velhice. Belo Horizonte: Arraes, 2015.

LOPES, Ruth Gelehrter da Costa; OLIVEIRA, João Batista Alves de. Cuidados paliativos: A necessidade na medicina atual diante do paciente fora da possibilidade terapêutica de cura. Prática Hospitalar, ano IX, n. 51, maio-jun. 2007.

MELO, Ana Georgia Cavalcanti de. Os cuidados paliativos no Brasil. Revista Brasileira de Cuidados Paliativos, ano 1, vol. 1, n. 1, 2008, Disponível em http://www.cuidadospaliativos. com.br/img/din/file/RBCP1.pdf. Acesso em 26.7.2016. 
MOTA, Joaquim Antônio Cesar; OLIVEIRA, Benigna Maria de; VALADARES, Maria Thereza Macedo. Cuidados paliativos em pediatria: uma revisão. Rev. Bioét. vol.21 no.3 Brasília set./ dez. 2013. Disponível em http://www.scielo.br/scielo.php?script=sci_arttext\&pid=S1983$80422013000300013 \&$ lng $=p t \& n r m=$ iso. Acesso em 25.7.16.

MOUREIRA, Diogo Luna. Pessoas e autonomia privada: dimensões reflexivas da racionalidade e dimensões operacionais da pessoa a partir da teoria do direito privado. Rio de Janeiro: Lumen Juris, 2011.

NUNES, Rui; SILVA, Filipa Martins. Caso belga de eutanásia em crianças. Rev. Bioét.vol.23 no.3Brasíliaset./dez.2015. Disponível emhttp://www.scielo.br/scielo.php?script=sci_ arttext\&pid=S1983-80422015000300475\&lng=pt\&nrm=iso. Acesso em 27.7.16.

PATIÑO, Ana Paula Corrêa. Limitações ao direito de recusar tratamento médico ou intervenção cirúrgica. São Paulo: Universidade de São Paulo, Faculdade de Direito, 2005, Dissertação (Mestrado).

PERLINGIERI, Pietro; D'ADDINO, Paola. Manuale di diritto civile. 5. ed. Napoli: ESI, 2005.

RODOTÀ, Stefano. Politici, liberateci dalla vostra coscienza. Disponível em: http://daleggere. wordpress.com/2008/01/13/stefano-rodota-\%C2\%ABpolitici-liberateci-dalla-vostracoscienza\%C2\%BB/. Acesso em: 20 jul. 2016.

SÁ, Maria de Fátima Freire de; MOUREIRA, Diogo Luna. Autonomia para morrer: eutanásia, suicídio assistido, diretivas antecipadas de vontade e cuidados paliativos. $2^{\mathrm{a}}$ ed. Belo Horizonte: Del Rey, 2015.

SÁ, Maria de Fátima Freire de; NAVES, Bruno Torquato de Oliveira. Manual de biodireito. $3^{\mathrm{a}}$ ed. Belo Horizonte: Del Rey, 2015.

SILVA, Marcelo Lucas Sarsur da. Do direito a não sentir dor: fundamentos bioéticos e jurídicos do alívio da dor como direito fundamental. Tese (doutorado) 2014. 141 fls. Universidade Federal de Minas Gerais, Faculdade de Direito, Belo Horizonte, 2014.

TEIXEIRA, Ana Carolina Brochado. Saúde, corpo e autonomia privada. Rio de Janeiro: Renovar, 2010.

THIENPONT Letal. Euthanasia requests, procedures and outcomes for 100 Belgian pacients suffering from psychiatric disorders: a retrospective, descriptive study. BMJ Open, 2015; 5: e007454.

Recebido em: setembro/2016

Aprovado em: julho/2017 